\title{
Photodegradation and Mineralization of Acetic Acid by Titanium Dioxide Films

\author{
Yulian Quan
}

\author{
Department of Environmental Engineering, Environmental Management College of China, \\ Qinhuangdao, 066102, China \\ email: quanyulian@126.com
}

Keywords: $\mathrm{TiO}_{2}$ /ITO film; Acetic Acid; Photocatalytic degradation; Mineralization

\begin{abstract}
ITO (indium-tin oxide) conductive glass plates were used as a support of Titanium dioxide films. $\mathrm{TiO}_{2} / \mathrm{ITO}$ films were prepared by sol-gel and dip-coating method with cheap inorganic salt $\mathrm{TiCl}_{4}$ as a precursor. The photocatalytic activity was evaluated by the photocatalytic decomposition of acetic acid in aqueous solution. Results showed that the photocatalytic activity of $\mathrm{TiO}_{2} / \mathrm{ITO}$ films was $20 \%$ higher than that of $\mathrm{TiO}_{2}$ nanopowders for the degradation of acetic acid. The removal rate of acetic acid $(25 \mathrm{mg} / \mathrm{L})$ was about $80 \%$ after $6 \mathrm{~h}$ irradiation, while $\mathrm{TiO}_{2} / \mathrm{ITO}$ film calcined at $500^{\circ} \mathrm{C}$ for $1 \mathrm{~h}$ with 4 -coating times was used as photocatalyst. Furthermore, $74 \%$ of the total organic carbon was eliminated after $6 \mathrm{~h}$ irradiation. It was founded that when the initial concentration of acetic acid was smaller than $40 \mathrm{mg} / \mathrm{L}$, the photodegradation of acetic acid accorded with first-order kinetic pattern.
\end{abstract}

\section{Introduction}

In recent years, environmental pollution has attracted considerable attention of many researchers. Undoubtedly, disposal of organic contaminants in the aqueous solution is the most important in the control of environmental pollution. Titanium dioxide has wide foreground in environmental applications [1][2] for its strong oxidizing powder, nontoxicity and long-term photostability. However, it is not easy to reclaim and reutilize $\mathrm{TiO}_{2}$ nanoparticles, which limited its application. Researchers immobilized $\mathrm{TiO}_{2}$ on appropriate support [3][4] in order to reutilize it. In this study, we chose ITO (indium-tin oxide) conductive glass plates as a support of $\mathrm{TiO}_{2}$ films because its conductive property impeded charge-carrier recombination. Other researchers have also proved the advantages of ITO as substrate [5][6]. Acetic acid is the main contaminant in the furfural waste water, which counts to $1.0-2.5 \%$ [7]. While acetic acid is one of the biodegradable organic matter and it is also the final product of most chemical oxidation[8][9], whose removal rate has a direct impact on the mineralization effect of the parent compound. To our knowledge, the study regarding photocatalytic degradation of acetic acid is very limited. In this study, $\mathrm{TiO}_{2} / \mathrm{ITO}$ films prepared by sol-gel and dip-coating method were used in the process of photodegradation and mineralization for acetic acid. Influencing factors of degradation were explored and based on the optimization of process parameters the dynamic mechanism of acetic acid degradation and its mineralization extent were further analyzed. Results of this study should provide a theoretical basis for the photocatalytic oxidation of refractory organic pollutants. And it would be useful attempt to apply $\mathrm{TiO}_{2} / \mathrm{ITO}$ films technology tothe actual water treatment.

\section{Experimental Section}

Preparation of $\mathrm{TiO}_{2} / \mathbf{I T O}$ Films. All the reagents were of analytical grade and were used without further purification. $2 \mathrm{ml}$ of Titanium tetrachloride was added slowly to $500 \mathrm{ml}$ of the cold $\left(0^{\circ} \mathrm{C}\right)$ ultrapure water $(16 \mathrm{M} \Omega \cdot \mathrm{cm})$ with acutely continuous stirring. After being dialysed, $\mathrm{TiO}_{2} \mathrm{water}$ sol was evaporated under agitation in $60^{\circ} \mathrm{C}$ water bath until the volume decreased to $80 \mathrm{~mL}$. Steady transparent $\mathrm{TiO}_{2}$ gel was obtained after aggregating for several days. If water in the $\mathrm{TiO}_{2}$ water sol was completely evaporated, $\mathrm{TiO}_{2}$ powder photocatalyst was obtained afrer calcination. The cleaned ITO conductive glass plates $(75 \mathrm{~mm} \times 40 \mathrm{~mm} \times 2 \mathrm{~mm})$ were dipped in the $\mathrm{TiO}_{2}$ gel and withdrawn at a 
rate of $10 \mathrm{~mm} / \mathrm{s}$. After each immersion, the films were dried in the infrared airer. By repeating the above procedure, $\mathrm{TiO}_{2} / \mathrm{ITO}$ films with different dip-coating times were obtained. There were interference stripes and metalline luster on its surface. After further heat treatment $\mathrm{TiO}_{2} / \mathrm{ITO}$ films used in photocatalytic reaction were obtained. However, calcinations above $550^{\circ} \mathrm{C}$ was not attempted since the ITO glass was distorted upon that temperature.

Photodegradation Experiments. $500 \mathrm{~mL}$ of acetic acid solution ((its initial concentration was $25 \mathrm{mg} / \mathrm{L}$ ) was added into self-made quartz reactor while $\mathrm{TiO}_{2} / \mathrm{ITO}$ film was fixed on the side of the reactor. The geometric area of the film inserted into solution was typically about $2.8 \mathrm{~cm}^{2}$. The solution was magnetically stirred, while the air was bubbled to the bottom of the reactor, whose flow rate was 0.8L/min. 400W high pressure mercury lamp (GYZ400, Foshan Electrical and Lighting Co., Ltd.) was installed on the side of reactor, which was $10 \mathrm{~cm}$ away from the center of the reactor. After the light was turned on, some reaction solution was withdrawn from the reactor at given time intervals and filtered by the membrane of $0.22 \mu \mathrm{m}$ for analyses of acetic acid(Waters Breeze HPLC System, American Waters Co.) [10] and total organic carbon levels(Model TOC- $\mathrm{V}_{\mathrm{CPH}}$, Japan Shimadzu Co.).

\section{Results and Discussion}

Effect of Heat Treatment on Photodegration. Fig.1 and Fig.2 show respectively the effect of temperature and time of heat treatment for $\mathrm{TiO}_{2} / \mathrm{ITO}$ film coated four times on the photodegradation of acetic acid. As can be seen from Fig. 1, When treated temperature was increased from $100^{\circ} \mathrm{C}$ to $500{ }^{\circ} \mathrm{C}$, the activity of $\mathrm{TiO}_{2} / \mathrm{ITO}$ film also rose. The activity was highest at about $500{ }^{\circ} \mathrm{C}$, where $\mathrm{TiO}_{2}$ film exhibited crystallization of anatase structure, but it began to decrease above $500^{\circ} \mathrm{C}$. This result possibly had relations to the crystal structure of $\mathrm{TiO}_{2} / \mathrm{ITO}$ film surface at the different treated temperature [11]. According to Fig.2, the activity of $\mathrm{TiO}_{2} / \mathrm{ITO}$ film was lower for $0.5 \mathrm{~h}$ while degration rate was $26.5 \%$, which went to the climax as heating for $1 \mathrm{~h}$ while degration rate was $58.7 \%$. However, the activity dropped with lengthening calcination time. On the basis of the above results, we adopted $\mathrm{TiO}_{2} / \mathrm{ITO}$ film treated at $500^{\circ} \mathrm{C}$ for $1 \mathrm{~h}$ as photocatalyst in the following experiments.

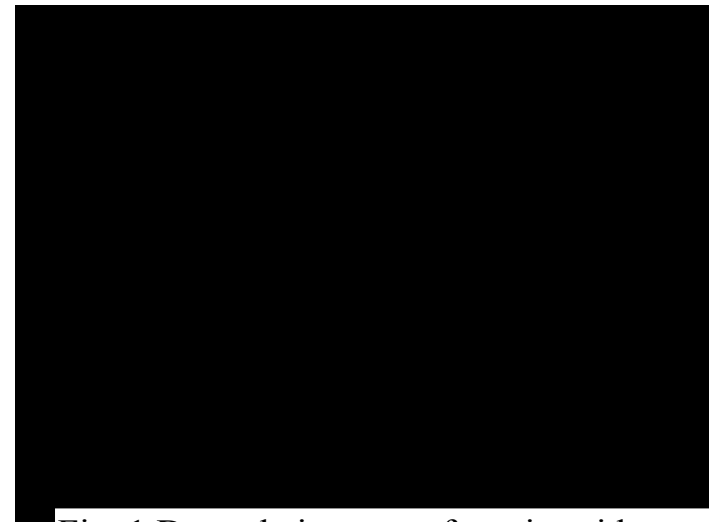

Fig. 1 Degradation rate of acetic acid on samples treated at different temperature for $1 \mathrm{~h}$

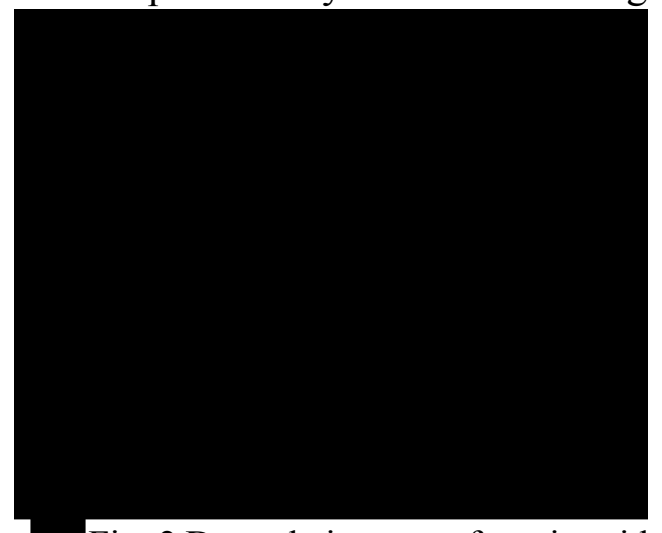

Fig. 2 Degradation rate of acetic acid on samples treated at $500^{\circ} \mathrm{C}$ for different

Effect of Initial Concentration of Acetic Acid. The effect of initial acetic acid concentration on photodegradation efficiency is shown in Fig.3. It is observed that the photodegradation conversion of acetic acid decreased with an increase in the initial acetic acid concentration. The initial photocatalytic rates( $\mathrm{r}_{0}$ ) were obtained according to Langmuir-Hinshelwood kinetics equation (Abbreviated to L-H model) and the initial acetic acid concentration $\left(\mathrm{c}_{0}\right)$. The relationship between initial photocatalytic reaction rates $\left(r_{0}\right)$ and initial acetic acid concentration $\left(c_{0}\right)$ was illustrated in Fig.4. when $\mathrm{c}_{0} \leqslant 40 \mathrm{mg} / \mathrm{L}$, the rectant molecules on the surface of $\mathrm{TiO}_{2} / \mathrm{ITO}$ film did not attain saturated absorption, reaction rate was mainly determined by the reactant concentration so that $\mathrm{r}_{0}$ swiftly increased with incresing $\mathrm{c}_{0}$, the photocatalytic reaction of acetic acid is a first-order reaction. When $\mathrm{c}_{0} \geqslant 40 \mathrm{mg} / \mathrm{L}, \quad \mathrm{r}_{0}$ increased slowly with the increase of $\mathrm{c}_{0}$, the absorption of the reactant molecules on the surface of $\mathrm{TiO}_{2} / \mathrm{ITO}$ film gradually reached saturation. Therefore the reaction rate 
completely depends on the amount of electrons and holes, it has nothing to do with the reactant initial concentration. The photodegradation of acetic acid accorded with zero-order kinetic pattern. The above results exactly coincided with L-H model.

Fig. 3 Effect of initial acetic acid concentration on photodegradation rate

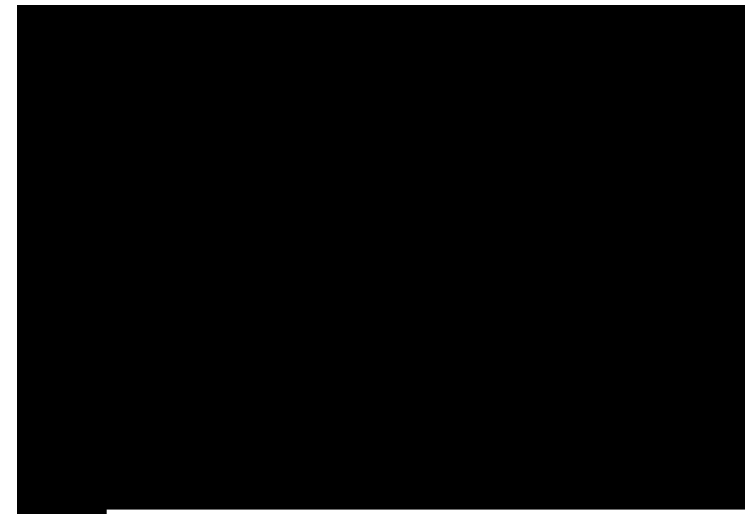

Fig. 4 Relationship between solution initial concentration and initial rate

Degration Efficiency of $\mathrm{TiO}_{2} /$ ITO Films with Different Dip-coating Times. The effect of dip-coating times on the degradation of acetic acid was illustrated in Fig.5. When the coating times from 1 to 4, quantity of $\mathrm{TiO}_{2}$ involved in the photodegradation reaction on the film surface increased gradually, and photocatalytic activity enhanced also. The photocatalytic activity of $\mathrm{TiO}_{2} / \mathrm{ITO}$ film reached the highest value with 4-coating times. However, with increasing the coating times, the multi-layered films undergone a relatively long calcination time and contained larger $\mathrm{TiO}_{2}$ particles[11], which led to efficient surface area in relation to photocatalytic reaction decreases, and then the photocatalytic activity weakened. It was also founded in Fig.5 that the photoactivity of $\mathrm{TiO}_{2} /$ ITO film was $20 \%$ higher than that of $\mathrm{TiO}_{2}$ powder. Because ITO conductive glass had the favorable electric property and good transmittance to the visible light, on whose surface there was a layer of $\mathrm{SnO}_{2}$ film immersed Indium. Therefore, as substrate of $\mathrm{TiO}_{2} / \mathrm{ITO}$ film, ITO not only effectively restrained charge recombination of the photogenerated electron/hole pairs but also accelerated formation of more hydroxyl radicals that have powerful oxidation function [12].

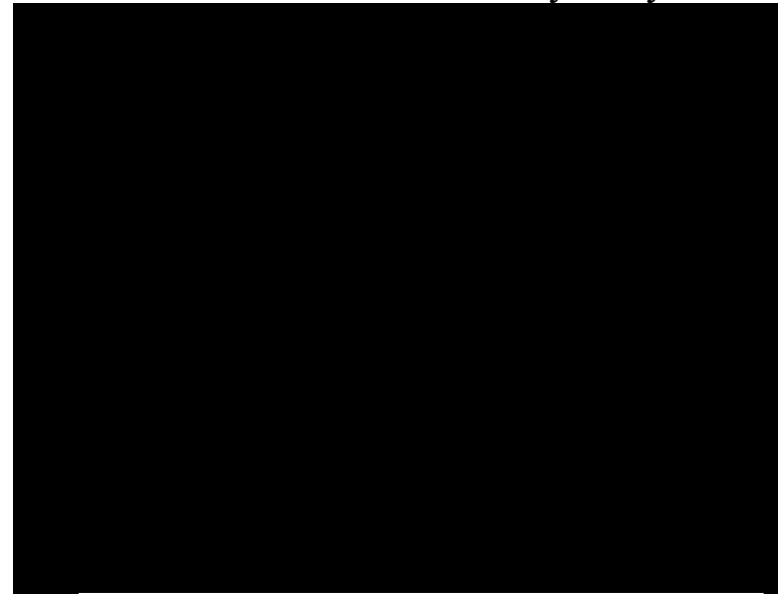

Fig. 5 Effect of dip-coating times on the degradation of acetic acid

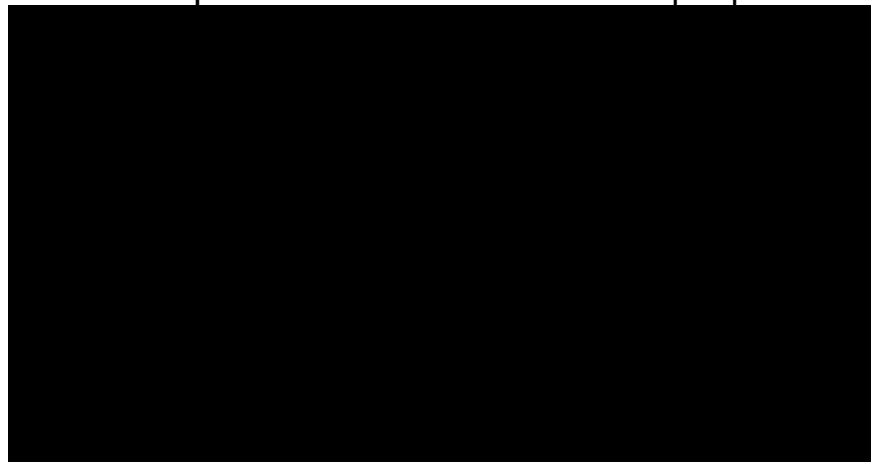

Fig. 6 Change of residual rate of TOC or Acetic Acid

(a) variation of TOC with ITO present;

(b) degradation of acetic acid with ITO present;

(c) variation of TOC with $\mathrm{TiO}_{2} / \mathrm{ITO}$ present;

(d) degradation of acetic acid with $\mathrm{TiO}_{2} /$ ITO present.

TOC Removal in the Photodegradation

photodegradation of acetic acid with $\mathrm{TiO}_{2} / \mathrm{ITO}$ film and ITO is showed in Fig.6. About $48 \%$ of acetic acid with initial concentration at $25 \mathrm{mg} / \mathrm{L}$ and $75 \%$ of the total organic carbon was remanent after $6 \mathrm{~h}$ irradiation with ITO present. The residual rate of TOC was always more than that of acetic acid. It was suggested that acetic acid woas decomposed into some smaller molecule compounds that affected the TOC amount. After $\mathrm{TiO}_{2} / \mathrm{ITO}$ film coated four times was added to the reaction, about $20 \%$ of acetic acid and $26 \%$ of the total organic carbon was remanent after $6 \mathrm{~h}$ irradiation. The residual rate of TOC is a little more than that of acetic acid. Yet they synchronously decreased with increasing 
illumination time. The reason may be that acetic acid and byproducts in the photodegradation were photodegradated at same time by $\mathrm{TiO}_{2} / \mathrm{ITO}$ film.

\section{Conclusion}

Photocatalytic degradation of acetic acid was accomplished with $\mathrm{TiO}_{2} / \mathrm{ITO}$ films, which were prepared by sol-gel and dip-coating method with cheap inorganic salt $\mathrm{TiCl}_{4}$ as a precursor. Effect of various parameters such as heat-treated temperature and time, coating layers of $\mathrm{TiO}_{2}$ film and the initial concentration of solution on the activity were investigated to study the optimal photocatalytic condition of acetic acid. According to the results, the photocatalytic activity of $\mathrm{TiO}_{2} / \mathrm{ITO}$ films was $20 \%$ higher than that of $\mathrm{TiO}_{2}$ nanopowders for the degradation of acetic acid. The removal rate of acetic acid $(25 \mathrm{mg} / \mathrm{L})$ was about $80 \%$ after $6 \mathrm{~h}$ irradiation, while $\mathrm{TiO}_{2} / \mathrm{ITO}$ film calcined at $500^{\circ} \mathrm{C}$ for $1 \mathrm{~h}$ with 4 -coating times was used as photocatalyst. Furthermore, $74 \%$ of the total organic carbon was eliminated after $6 \mathrm{~h}$ irradiation. It can be presumed that acetic acid and byproducts in the photodegradation of acetic acid were photodegradated at same time by $\mathrm{TiO}_{2} / \mathrm{ITO}$ film. When the initial concentration of acetic acid was smaller than $40 \mathrm{mg} / \mathrm{L}$, the photodegradation of acetic acid accorded with first-order kinetic pattern. This study provided a foundation for $\mathrm{TiO}_{2} / \mathrm{ITO}$ films process to be used in actual water treatment.

\section{References}

[1] Hoffmann M R, Martin S T, Choi W, et al. Environmental applications of semiconductor photocatalysis [J]. Chemical Reviews, 1995 (95) 69-96.

[2] Ge B, Zhang J, Lei P. Study on degradation behavior of N,N-dimethylacetamide by photocatalytic oxidation in aqueous $\mathrm{TiO}_{2}$ suspensions [J]. Desalination and Water Treatment, 2012 (42) 274-278.

[3] Guo H, Kemell M, Heikkilä M. Noble metal-modified $\mathrm{TiO}_{2}$ thin film photocatalyst on porous steel fiber support [J]. Applied Catalysis B, 2010 (95) 358-364.

[4] Plesch G, Vargová M, Vogt U F. Zr doped anatase supported reticulated ceramic foams for photocatalytic water purification [J]. Materials Research Bulletin, 2012 (47) 1680-1686.

[5] He C, Xiong Y, Zhu X. Improving photocatalytic activity of $\mathrm{Cu}$-loaded $\mathrm{TiO}_{2}$ film using a pulse anodic bias [J]. Catalysis Communications, 2003 (4) 183-187.

[6] Zainal Z, Saravanan N, Fang N S. Electrochemical assisted photodegradation of oxalate ions using sol-gel coated $\mathrm{TiO}_{2}$ on ITO glass [J]. Materials Science \& Engineering B, 2004 (111) 57-63.

[7] Zhang X H, Liu J Q, Jia Y L. Reclaim process of acetic acid in waste water of furfural production [J]. Chinese Chemical Industry and Engineering. 2006 (23) 143-146.

[8] Kozlov D V, Paukshtis E A, Savinov E N. The comparative studies of titanium dioxide in gas-phase ethanol photocatalytic oxidation by the FTIR in situ method [J]. Applied Catalysis B, 2000 (24) 7-12.

[9] Jerry C, Meryer P A, Marrone J W T. Acetic acid oxidation and hydrolysis supercritical water [J]. AIChe Journal, 1995 (41) 2108-2121.

[10] Kang C L, Wang Y, Yu H B. Determination of acetic acid in furfural waste water by high performance liquid chromatography [J]. Chinese Journal of Jilin University(Science Edition), 2004 (42) 465-470.

[11] Sui H Q, Kang C L, Quan Y L, Preparation and characterization of ITO-supported $\mathrm{TiO}_{2}$ photocatalyst [J]. Chinese Science Technology and Engineering, 2009 (9) 558-560.

[12] Liu F X, Cui Z L, Zhang Z K. Photocatalytic degradation of methyl orange by Nano-TiO 2 films [J]. Chinese Imaging Science and Photochemistry, 2003 (21) 119-125. 